\title{
Industrial robotic machining: a review
}

\author{
Wei $\mathrm{Ji}^{1}(\mathbb{D}) \cdot$ Lihui Wang ${ }^{1}$
}

Received: 28 August 2018 / Accepted: 29 January 2019 / Published online: 3 April 2019

(C) The Author(s) 2019

\begin{abstract}
For the past three decades, robotic machining has attracted a large amount of research interest owning to the benefit of cost efficiency, high flexibility and multi-functionality of industrial robot. Covering articles published on the subjects of robotic machining in the past 30 years or so; this paper aims to provide an up-to-date review of robotic machining research works, a critical analysis of publications that publish the research works, and an understanding of the future directions in the field. The research works are organised into two operation categories, low material removal rate (MRR) and high MRR, according their machining properties, and the research topics are reviewed and highlighted separately. Then, a set of statistical analysis is carried out in terms of published years and countries. Towards an applicable robotic machining, the future trends and key research points are identified at the end of this paper.
\end{abstract}

Keywords Robotic machining $\cdot$ Machining vibration $\cdot$ Trajectory planning $\cdot$ Machining process

\section{Introduction}

The future manufacturing is characterised by high customisation. Here, machining is one of the most important processes from raw materials to final products in manufacturing industries [1]. Currently, CNC machine tool is a majority performing machining operations, since they are able to deliver higher machining accuracy with high stability [2]; however, simultaneously, their costs are high and their functions are single. Therefore, a multi-function and low-cost machine is a trend to replace the current machine tools, e.g. industrial robot (IR) could be a potential one. During the past 30 years, the applications of IRs are dramatically increased. According to the report of International Federation of Robotics [3], the number between 2011 and 2016 was raised to 212,000 units, compared with the average annual number of robots sold between 2005 and 2008, about 115,000 units, which is an 84\% increment, and the estimated number in 2020 is 520,900 units. IRs are generally applied to performing tasks including pick and place, welding, painting, packaging and labelling,

\section{Wei Ji}

1 KTH Royal Institute of Technology, 10044 Stockholm, Sweden palletizing, and product inspection, towards industrial automation. The research on robotic machining was proposed first to replace the human operators on a shop floor in 1987 by Appleton and Williams [4], in which a serial of robot applications including drilling, grinding and deburring were presented.

The major problems limiting application of robotic machining are related to material removal rate (MRR) of the machining operations. (1) In low-MRR operations, mass programming work caused by the flexibility of IRs is a major weakness since the IRs are supposed to replace human operators; while (2) low machining quality caused by the low stiffness of IRs is the major drawbacks in high-MRR machining operations, since the operations are carried out in machine tools in conventional environments. To solve the problems, there have been numerous research publications as well as technical reports for more than three decades. It is also evident that the trend of robotic machining research has also undergone drastic changes. To the best of the authors, there has not been a comprehensive review on robot machining; therefore, the aim of this article is to provide a comprehensive review on robotic machining. The remainder of paper is organised as follows: Sect. 2 introduces the review papers on robotic machining and gives overall research topics of robot machining. Section 3 is a main section describing various technologies developed or implemented after proposing robotic machining 
concept. Recap on research topics and a set of statistical analysis are presented in Sect. 4. Section 5 concludes this paper.

\section{Previous reviews and major research topics of robotic machining}

Robotic machining generally refers to soft materials and hard materials. Soft material machining was employed in rapid prototyping by IRs [3-14], in which machining quality requirement is not as critical as hard material machining. And, this paper only presents robotic machining of hard materials. Also, parallel machine was proposed as an alternative of machine tools to overcome the cumulative error of conventional machine tool structure, of which flexibility is not as high as IR. Therefore, these two parts are not included.

\subsection{Previous review papers}

So far, there are six reported review papers on robot machining including two journal articles and four conference papers. In 2011, Pandremenos et al. [15] reviewed machining with robots in terms of accuracy issue, chatter, calibration and programming. However, there were limited publications at that moment (about 75\% publications reported after 2012, as shown in Sect. 4.3). In 2013, Chen and Dong [16] reviewed robot machining: recent development and future research issues; they highlighted robot-machining efficiency analysis, stiffness map-based path planning, robotic arm link optimization, planning and scheduling for a line of machining robots. Karim and Verl [17] investigated the challenges in robot machining. Their results showed that the major problems are insufficient rigidity, poor accuracy and complex programming. In 2015, Bo et al. [18] reviewed robot in finished from control strategy point of view. From their analysis, impedance control and adaptive impedance control might be a solution in robot-machining application. In the same year, Iglesias et al. [19] reviewed the status and potential of robot machining, and emphasised that the positioning accuracy as well as the trajectory accuracy, which includes dynamic effects. Yuan et al. [20] reviewed machining chatter, and they highlighted that mode coupling effect should be considered, and the chatter model was simplified.

\subsection{Major research topics}

The problems are associated with the machining operations. Human like operation is a major direction for low-MRR operations referring to deburring, polishing and grinding; therefore, the major research involves sensor-based detection and high flexibility (Sect. 3.1). The high-MRR operations, drilling and milling, of which the requirements of machining quality are relatively high, challenge the robot stiffness, therefore, vibration suppression is a core research topic. To archive a qualified machining, robotic machining dynamics (robot stiffness and machining chatter in Sects. 3.2.1 and 3.2.2) are the keys. Robotic machining configurations are introduced in terms of the placement relationship between spindle and robot end effector (EE) (Sect. 3.3). The most challenging one is the most flexible configuration, spindle mounted on EE; therefore, the research works on that are presented, including trajectory planning (Sect. 3.4), machining process (Sect. 3.5), machining quality (Sect. 3.6), monitoring and compensation (Sect. 3.7), and other aspects (Sect. 3.8).

\section{Current research status}

\subsection{Low-MRR operations}

Sensor-based monitoring and online control were focused on towards a human-like operation of robotic low-MRR machining, since robotic machining was introduced to replace human operators [4]. Izumi et al. [21] proposed a method by which grinding robots were taught the contour information of workpiece surface. In their work, grinding torque and force were used to calculate the coordinates of the points of contour. Muto and Shimokura [22] developed a contact sensing-based approach to teach and control contour-tracking tasks in robot grinding. In their method, the force and velocity information on the contact point were detected and used. Similarly, Jinno et al. [23] proposed a force control method in which a force/torque sensor was mounted between robot $\mathrm{EE}$ and tool to increase the stability in grinding, chamfering and polishing. Their method enabled the tool to follow the workpiece shape under a relatively consistent force. Surdilovic et al. [24] proposed a comprehensive planning and a real-time control approach for robotic grinding and polishing. In their method, path governor function was developed to address non-linear effects of robot joint friction. Villagrossi et al. [25] proposed a control strategy to copy a human-like operation based on force feedback in deburring of hard material. In their method, the nominal deburring trajectory was adjusted and deformed making multiple repetitions until the nominal deburring path was completed. Domroes et al. [26] proposed a force control strategy employed in a force sensor mounted between robot arm EE and spindle. By considering configurations, robotic belt grinding was focused on. Chen et al. [27] developed two degrees of freedom (DoF) contact force control method for robotic blisk grinding, which provided a reference for grinding path generation. The method could avoid over-ground area on the blisk. Ding et al. [28] proposed a method combining force feedback and generated trajectory, in which an adaptive proportional-integral control algorithm was developed to guarantee to evaluate the stiffness of polishing system and to adjust the relevant parameters. The method could improve polished surface qualities experimentally. 
Machining quality was another important topic on top of an archived human-like operation. Leali et al. [29] developed an offline programming method for robot deburring of aerospace components. In their research, costs and times, learning easiness, production downtimes and machining accuracy were compared in two programming methods which can perform the machining with in the required tolerances. Rafieiana et al. [30] researched regenerative instability of impact-cutting material removal in the grinding process performed to improve grinding quality. Their results showed that a stable grinding was delivered. Liu et al. [31] proposed a robotic polishing system which was equipped with a special designed polish spindle. Their experimental results demonstrated their robotic polishing system performed well by producing a sharp tool influence function. Xie et al. [32] developed an active contact flange which is mounted between EE and grinding spindle. A set of experiments was carried out, of which result showed that the surface roughness was improved compared with manual operation. Sufian et al. [33] focused on the quality and the accuracy of size and form in robot grinding. Their results showed that the low robot speed could improve the repeatability in terms of the indexes. Due to high stability of robotic belt grinding, the grinding quality has been focused on. Li et al. [34] proposed a 3D shape matching of a blade surface in robotic grinding including robot handle the blade, and grind tools were fixed. In their method, a laser scanner was used to obtain the shape of the blade, which helps to improve grinding accuracy. Under the similar setups, Mao et al. [35] considered the trajectory generation by material removal perspective in robot grinding. Their method could be used to obtain a higher accuracy. A searchbased collision-free planning algorithm was developed for grinding welt grinding to deliver a stable robotic grinding [36]. Yan et al. [37] proposed a grinding force model consisting of sliding, ploughing and cutting components, especially the effects of cut-in and cut-off of grinding process. Their results showed that a proper combination of process parameters could archive a relatively stabile machining, and a $\mathrm{Ra} 0.4-\mu \mathrm{m}$ surface roughness. In addition, an automatic fixture was developed to aid the robotic deburring for large aircraft components [38].

A high-flexibility vision of robotic machining was targeted associated with robot arm, moveable platform and sensors, in which plenty of hardware and software are integrated together. Therefore, research on manufacturing system, automatic programming and communication interface were carried out recently. Huang et al. [39] developed a robotic system for repairing of $3 \mathrm{D}$ profile turbine vane airfoil. In the system, grinding and polishing were the two operations. Ricardo et al. [40] proposed a novel approach of automatic programming, in which the model of product, process and resource were considered, as well as DoFs of robot, deburring process and trajectory generation to reduce the deburring errors. In an EU project, COROMA (https:/www.coroma-project.eu/), robot arm was proposed mounted on a moveable platform to perform machining tasks, which extends the robot application range on a shop floor. In this case, the research trends to software engineering side. On top of COROMA, an architecture was proposed to address the communication issues between hardware, software and human operators [41] , which provides an easy way for robot relevant operations. A new concept with an even higher flexibility is proposed by combining holon concept with cyber physical system [42], in which robotic machining operation could be reconfigured according to the upcoming tasks. In addition, a 3D vision system to detect workpiece for robotic grinding system was developed by Diao et al. [43] to enhance the function of robotic machining system.

In general, integration technology is a foundation of the modern robotic machining for low-MRR operations to guarantee the machining system to work robustly and safely, which is a key to decide applicability of a system. On top of that, a close loop control is another key referring to both a sensor-based detection and an intelligent decision-making which rely on a comprehensive understanding of the machining process.

\subsection{Robotic machining dynamics}

Robotic machining stability is closely related to robot stiffness and machining vibration which are reviewed in this section.

\subsubsection{Robot stiffness}

Low stiffness is a major drawback for high-MRR operations, e.g. robotic milling and drilling. Robot stiffness refers to absolute stiffness and relative stiffness. The absolute stiffness can be improved by robot component improvement and control parameter optimisation, while the relative stiffness is workpiece placement and posture.

Control parameters are easily adjusted in a real-time way. Katic and Vukobratovic [44, 45] proposed a robot dynamicbased approach to optimise control parameters. In their method, the control parameters were determined according to dynamic environment and robot uncertainties based on a trained neural classifier. Stiffness modelling and real-time deformation compensation were combined by Zhang et al. [46]. Their results showed that a high productivity and a good surface accuracy could be archived. Dumas et al. [47] developed an approach to identify joint stiffness for any six-revolute IRs by considering both translational and rotational displacements of the robot EE for a given applied wrench (force and torque). In addition, robot components have been studied to enhance robot stiffness. Denkena et al. [48] proposed a special design and optimisation for machining application to improve the IR stiffness. Their designed two-axis robot was equipped with torque motors with load-sided high-resolution encoders in addition to conventional gear motors with harmonic drive gearboxes. The research on 
the robot components has not been reported in terms of improvement of machining application.

In robot workspace, robot stiffness partially relies on EE operation position, workpiece placement and postures. Caro et al. [49-51] proposed a workpiece placement optimisation approach in robotic machining by considering cutting condition and robot stiffness. The method worked well for a higher kinematic redundancy of robot. Garnier et al. [52] proposed a machining quality criterion including geometrical error and productivity to optimise the workpiece placement and the kinematic redundancy of the robot. Klimchik et al. [53, 54] tested a set of the parameters of robot machining by considering the circularity index evaluating. In their work, the workpiece placement, workspace size, required accuracy and payload were able to be taken in account. In addition, Subrin et al. [55] introduced a performance criteria to evaluate in a kinematical redundant robotic cell dedicated to a machining task. In their evaluation, the constraints of the machining processes, geometrical model and the kinematic model of robot arm are considered to be defined the optimised location for a rotary table and to analyse stiffness of manipulator.

Robot posture and workpiece placement are closely related to each other, and one fixed factor provides a constraint on the other one. A set of performance evaluation indexes were proposed by Lin et al. [56] to optimise the robot posture. The indexes involve kinematic performance index, body stiffness index and deformation evaluation index, as shown in Fig. 1, and the method was used to obtain a feasibility of the proposed performance evaluation indexes. By considering the displacement of the three points of EE, Xiong et al. [57] proposed a stiffness-based pose optimisation. The method could be integrated into $\mathrm{CAD} / \mathrm{CAM}$ software to convert a $\mathrm{CNC}$ programme into a robot programme. Xie et al. [58] presented a joint parameter error and robot stiffness-based posture optimisation in robotic milling. Within their method, the position of robot base frame and the rotation angle of tool at each cutter location (CL) point were used as redundant freedoms to extend optimal solution space. Mousavi et al. [59, 60] developed a multi-body dynamic model of a serial robot based on beam elements, of which parameters, beam element geometry, elasticity and damping, were adjusted based on experiments. In addition, tool centre point (TCP) and cutting tool direction were focused on towards a high-stiffness posture. Karim et al. [61] presented a detailed experimental modal analysis within robot workspace in machining, of which results demonstrated that high TCP positions tend to change the main oscillation direction, and linear interpolation for eigenfrequencies was recognised as unsuitable for some parts of the workspace. Cutting tool direction was optimised by $\mathrm{Bu}$ et al. [62]. In their method, a Cartesian compliance model of robot stiffness was developed, together with a quantitative evaluation index of processing performance. The experimental results showed that a higher accuracy of the countersink depth and hole axial direction could be guaranteed.

For the IR point-of-view, control parameter optimisation and robot component design are the major research points to enhance robot stiffness. Workpiece placement and robot posture are related to robot stiffness closely in terms of relative stiffness of IR.

\subsubsection{Machining vibration}

Machining vibration is a quite important topic for robotics machining since it is a major source of the vibration. Pan et al. [63] analysed the chatter in robotic machining process for the first time. Their results demonstrated that mode coupling chatter might happen, if the robot structure stiffness was not significantly higher than process stiffness. Then, by considering robot structure and identifying its parameters, Abele et al. [64] developed a model of the system stiffness and focused on its behaviour in milling process. With the information on the captured process forces and the compliance model, the tool path can be controlled and the accuracy of an IR for machining application can therefore be increased. A structural dynamics of an articulated manipulator with a spindle and a tool was modelled by Cordes et al. [65], of which predicted
Fig. 1 Concept of COmponents and METhods for adaptive control of industrial rob7ots (http://www.comet-project.eu/)

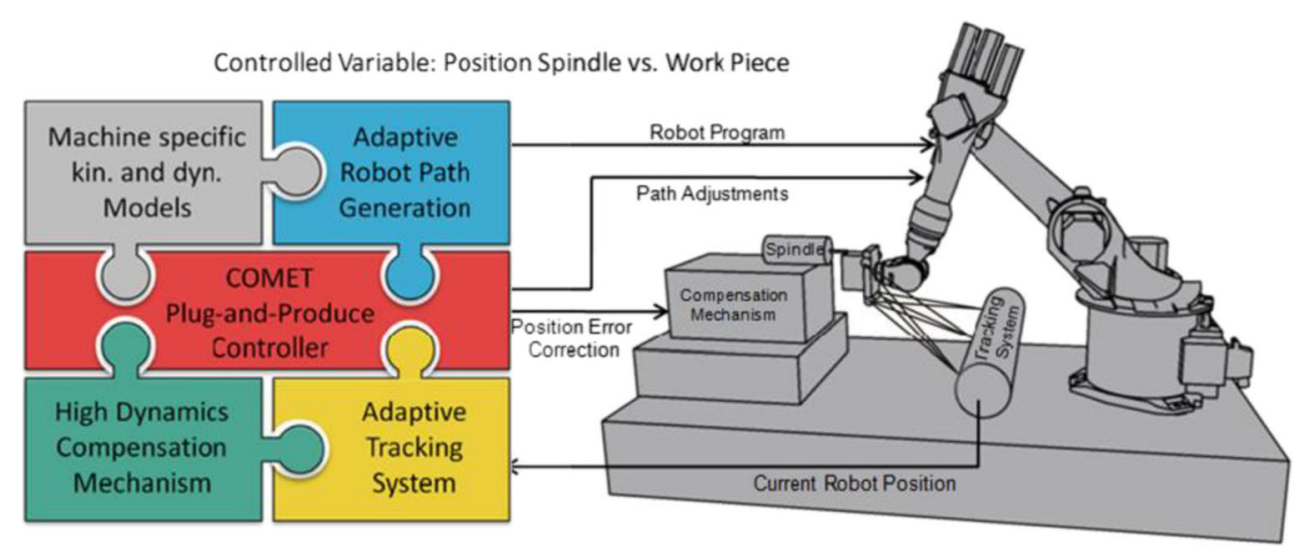


Fig. 2 A robot boring system with a pressure [71]
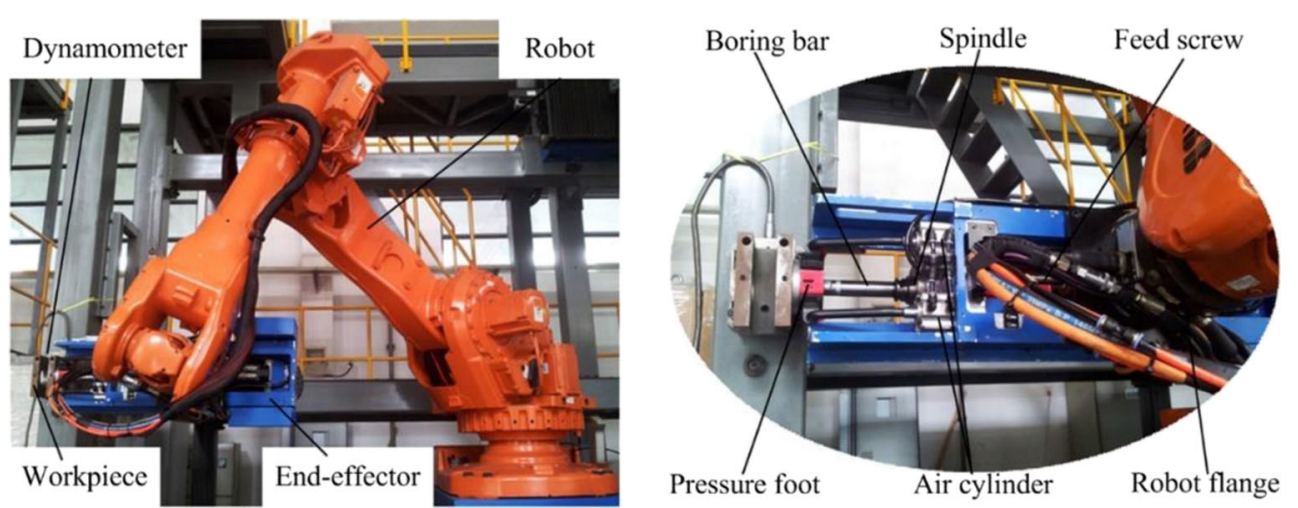

stability chart (predicted stability chart for an aluminium milling shown in Fig. 2) was experimentally validated. Their results showed that pose-dependent modes of robot structure were at low frequencies, and damped out by the machining process at high spindle speeds. Additionally, towards a realtime monitoring, a chatter prediction based on signal processing in time domain for robot milling process was developed by Safi et al. [66]. Their simulation results showed that the chatter limit of robotic machining was drastically influenced by changing robotic machining configuration.

Damping was employed in robotic machining to reduce machining vibration and to avoid machining chatter. A drive-based damping for robotic machining with secondary encoders was presented by Vieler et al. [67], which was implemented in feed drives successfully. Their results demonstrated that the stability in robotic machining could be ensured through the optimization of the robot configurations, without changing the cutting parameters. To suppress the machining chatter, Yuan et al. [68,69] developed a semi-active magnetorheological elastomers absorber mounted on tool handle. Their results demonstrated that a great amount of chatter severity was absorbed, and surface roughness was improved from $30 \%$ to nearly $50 \%$.

In summary, machining chatter is a hard and important topic in robotic machining due to low stiffness caused low productivity. In terms of avoidance of machining chatter, additional damping methods could provide a good way, as a short-term development of robotic machining; however, targeting a stable robotic machining, a comprehensive understanding on robotic machining system could be a long-term strategy.

\subsection{Robotic machining configurations}

In general, there are three reported configurations for robotic machining, $\mathrm{C} 1$ : a robot is used to handle workpiece, and the spindle is fixed [70]; C2: a special equipment including spindle is mounted on robot arm, and workpiece is fixed [71]; and C3: a spindle is mounted on robot arm, and the workpiece is fixed. The comparison between the above configurations is shown in Table 1, in terms of stability and flexibility of the configurations, allowed workpiece size, allowed operations and achievable machining qualities.

In general, the stability of $\mathrm{C} 1$ and $\mathrm{C} 2$ is higher, and their flexibilities are lower, compared with $\mathrm{C} 3$. In terms of workpiece size, under $\mathrm{C} 1$, only small workpiece can be handled due to payload limitation, whereas $\mathrm{C} 2$ and $\mathrm{C} 3$ do not limit workpiece size. Multi-operations can be performed under $\mathrm{C} 1$ and $\mathrm{C} 3$, whereas, only single operation, drilling, can be performed under $\mathrm{C} 2$. The high qualities can be archived under $\mathrm{C} 1$ and $\mathrm{C} 2$ which have relatively high stiffnesses; however, the one under $\mathrm{C} 3$ is low.

\subsubsection{Fixed spindle in robotic machining (C1)}

The setup, the fixed spindle with robot handling workpiece, was first designed and proposed by Puzik et al. [70, 72]. Based on the concept, Olofsson et al. [73] developed a set of models of the construction which is experimentally identified using subspace-based identification methods. By using the method, a subsequent control scheme, utilising state feedback for controlling the position of the spindle, is outlined. The research was supported by an EU/FP7-project: COMET (http://www.
Table 1 Application property comparison of configurations 1-3 of robotic machining

\begin{tabular}{llllll}
\hline $\begin{array}{l}\text { Configurations of robotic } \\
\text { machining }\end{array}$ & Application properties & & \\
\cline { 2 - 6 } & Stability & Flexibility & $\begin{array}{l}\text { Workpiece } \\
\text { size }\end{array}$ & $\begin{array}{l}\text { Allowed } \\
\text { operations }\end{array}$ & $\begin{array}{l}\text { Machining } \\
\text { quality }\end{array}$ \\
\hline C1 & High & Low & Small & Multi & High \\
C2 & High & Low & Any fixed & Single & High \\
C3 & Low & High & Any fixed & Multi & Low \\
\hline
\end{tabular}



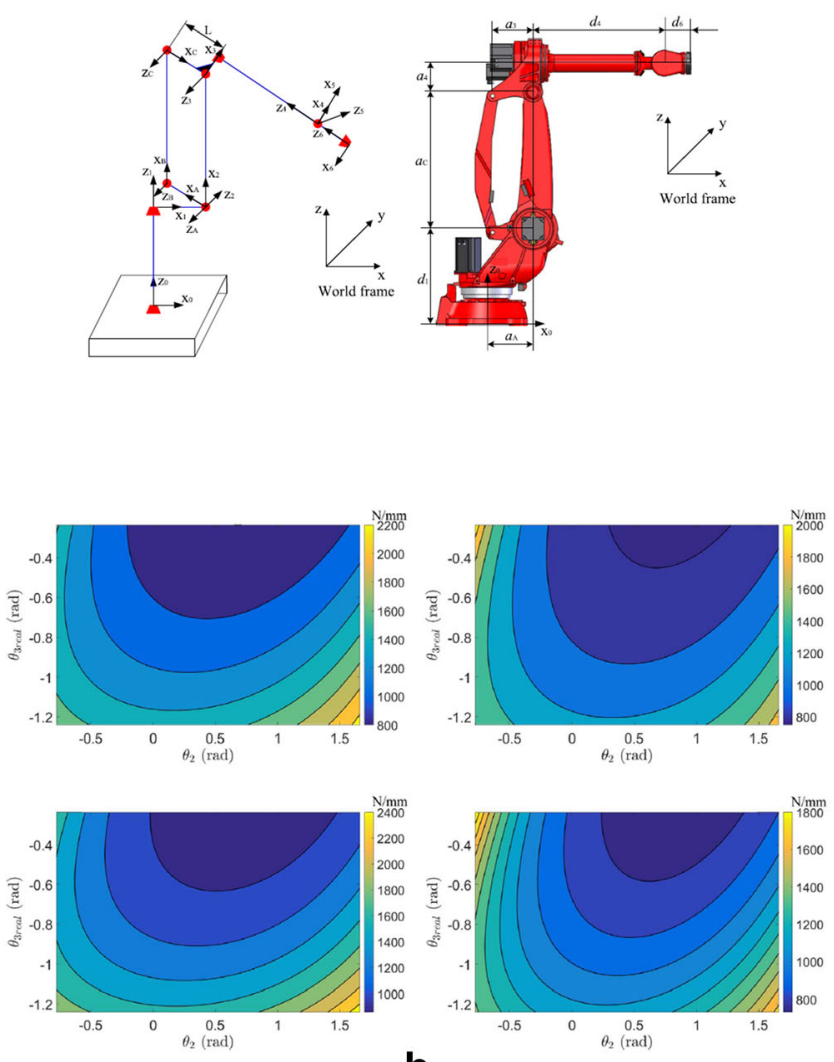

b
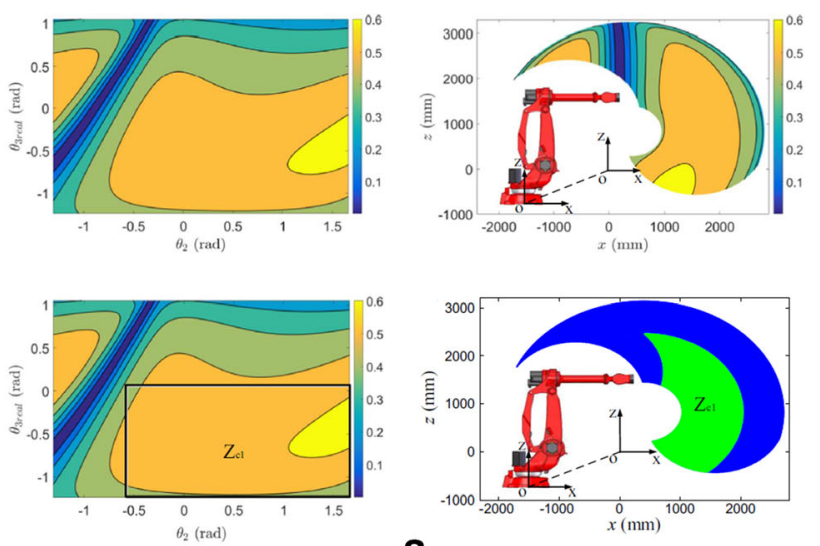

a
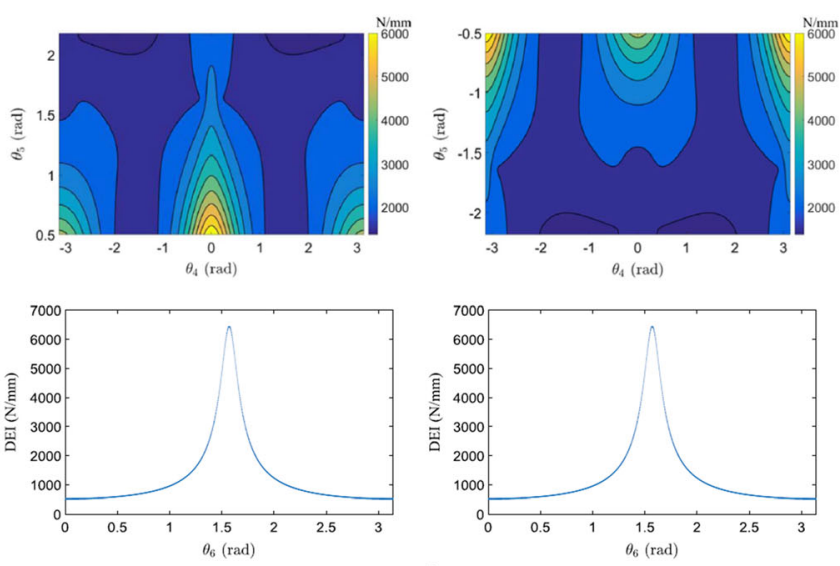

C

Fig. 3 The kinematic performance maps (a), stiffness performance maps (b) and the deformation maps (c) [56]

comet-project.eu/) in 2013, and an architecture with both offline and online compensations was proposed, as shown in Fig. 3, and detailed by Lehmann et al. [74].

Machining error was a major topic to be discussed. Schneider et al. [75] performed a set of experiments on machining source errors, in which environment-dependent, robotdependent and process-dependent errors were analysed and addressed, which showed that the compliance and the backlash were the most dominant sources. Given the dynamic properties to compensate the machining errors, Schneider et al. [76] developed an elastic solid-state joint-based method which allows to adjust system stiffness in two orthogonal directions independently. Then, a set of experiments were carried by Olof et al. [77], of which results showed that a milling accuracy $\pm 12 \mu \mathrm{m}$ was achieved in both face and radial milling. Schneider et al. [78] developed a feed forward-based method to model a stiffness model. Their approach was successfully used to compensate the errors caused by machining deformation. Then, Schneider et al. [79] proposed a modular approach including a predictive offline compensation of machining errors and an online compensation based on piezo-actuator basis. Haage et al. [80] introduced an offline compensation approach based on joint-motion simulation to improve the machining accuracy. Their method improved the machining accuracy significantly.
Moreover, to find the stiffest pose, Schneider et al. [81] introduced a set of potential criteria including EE stiffness, EE stiffness in force direction, damping, minimal joint movements, backlash avoidance, workpiece collision and reachability. Halbauer et al. [82] compared two types of milling strategies including circular tool paths with spiral step over and constant step over. Their results showed that the milling strategies influenced the effect of robot milling. In addition, based on CAM off-line programming, the setup was integrated into a robot cell by Leali et al. [83] to archive a reconfigurable machining cell.

In summary, the $\mathrm{C} 1$ with a fixed spindle enables the machining system stable enough to improve machining accuracy compared to the $\mathrm{C} 3$. Under the similar configuration, robotic belt grinding archives a better result, which is one of the results the machining systems are well employed in grinding of turbine blades. However, the size and weight of the allowed workpieces are constrained by the payload of IRs; therefore, the flexibility of $\mathrm{C} 1$ is much lower than $\mathrm{C} 3$.

\subsubsection{Robot boring system (C2)}

Target the drilling of the key connection holes on the aircraft, a special robot boring system mounted on IR's EE, including a robot flange interface, two air cylinders, a pressure foot, a feed 
screw, a spindle and a boring tool, was first proposed by Guo et al. [71], as shown in Fig. 4. The system was designed to suppress the vibration caused by the robot body considering vibration mechanism in the robotic boring process in order to overcome the low stiffness of IRs. On top of the method, cutting force, boring chatter and robot posture optimisation were researched. Wang et al. [84] developed dynamic cutting force model by using the principles of cutting mechanics and the Oxley orthogonal-cutting model. The errors of the predicted average cutting forces were within margin of $11 \%$ for stable boring and $21 \%$ for vibrated boring. Then, Wang et al. [85] studied chatter mechanism and stability, of which results demonstrated that feed rate and the depth of cut influenced the stability significantly, and that feed rate and depth of cut were two significant factors affecting the stability of the system. Recently, Guo et al. [86] proposed a robot posture optimization model and a positioning accuracy compensation model, by which a Ra 0.8 -hole surface was obtained, and a position accuracy of $0.05 \mathrm{~mm}$ and an orientation accuracy of $0.05^{\circ}$ were obtained for robot.

Under the same C2, Dong et al. [87] developed a rotary ultrasonic drilling of which device is mounted on IRs to reduce the cutting force and to suppress the lateral chatter. Compared with conventional method, the stabile range was extended. Then, they [88] extended the developed method to drill the carbon fibre reinforced polymers (CFRP)/aluminium, in which with a well understanding of the system, the burr height model could be established, and it was validated by a set of experiment. Ultrasonic machining could be a potential way of low-stiffness robotic machining.

Additional device in the configuration $\mathrm{C} 2$ is able to suppress machining vibration and to overcome the low stiffness of IR. The method can provide a feasible solution for robotic machining application with a single function.

\subsection{Trajectory optimisation}

Apart from CNC machine tool of which stiffness levels of axis are changed during movements within an acceptable range, IR stiffness is not stable enough during following a trajectory. Therefore, the trajectory planning is an important topic since the stiffness is changed during the trajectory. A path regulation [89]-based path planned algorithm was developed by Chin and Tsai [90], in which the similarity between CNC machine tool and robot was under consideration in terms of tracking a trajectory. However, the stiffness was not considered. Krži et al. [91] developed an offline programming method which could be used to overcome a kinematic constraint by considering EE rotation, part translation and part rotation. Their method could improve the speed and quality of calculating the valid configurations/tool path. Then, trajectory deviation and cutting force were considered by Slamani et al. [92, 93], and they tested different cutting conditions in high-speed robotic trimming of CFRP. Their results demonstrated that the medium cutting speed and low feed were the optimal cutting condition. Considering a feed direction stiffness, Xiong et al. [94] proposed a trajectory optimisation method in which the stiffness of the robot-machining system along the feed direction was maximised at per CL point. Based on robot compliance and milling forces, Villagrossi [95] used the joint stiffness matrix to optimise a milling trajectory. The milling process was improved; however, it was still poorer compared with conventional methods. He et al. [96] modelled a 2-DoF dynamic model of a robotic milling process, introduced modal analysis and robot kinematics, and proposed a new stiffness orientation method to optimise path. The experiments showed that the force was reduced, and stability was improved.

In addition, there is a special system of dual robotmachining structure; Owen et al. [97-99] introduced a realtime trajectory planner. In their method, to reduce joint accelerations contributing the most to the saturated joint torques, a weighted pseudo-inverse technique was employed. Then, by considering minimising the compliance factor of the manipulators based on a certain tool path based on workpiece, higher stiffness configurations could be obtained by their developed trajectory optimisation method, resulting a reduction of machining torque and deflection of tool $[100,101]$. Then, the conflicting performance criteria were added the model [102].
Fig. 4 Predicted stability chart for an aluminium milling process considering four modal subsystems [65]

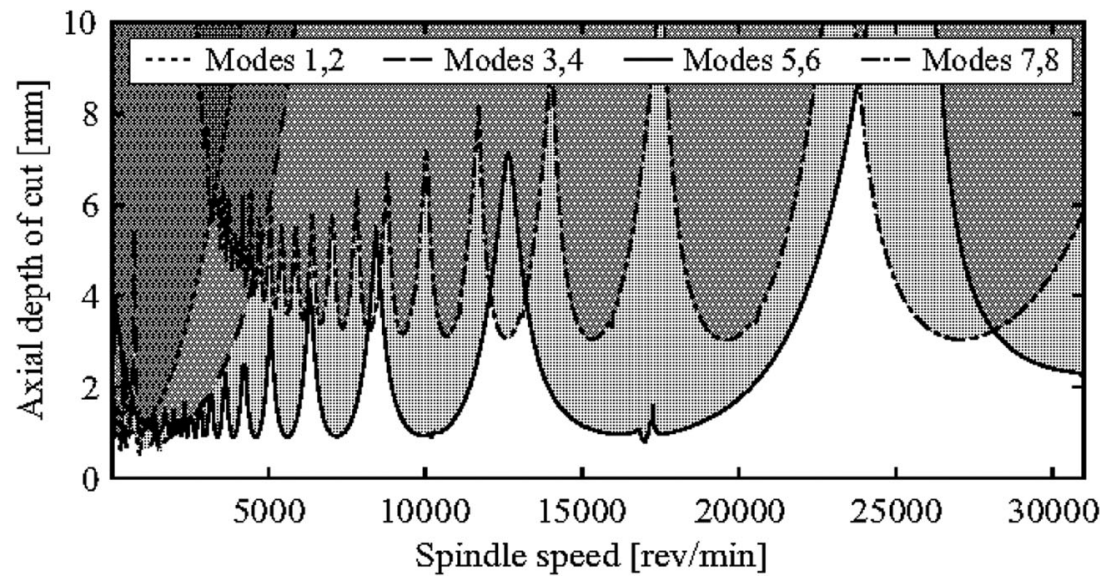


In corresponding with robot stiffness, robot trajectory optimisation, related to tool path of workpiece, has been studied to optimise the robot configuration, feed speed and orientation, and cutting condition along with the trajectory.

\subsection{Machining process}

Machining is one of the most complex processes within manufacturing area [103]; therefore, it is a big challenge for robot manipulator with low stiffness. Many topics related to robotic machining have been discussed in terms of factors with conventional CNC machining. Tool path generation is a major difference, in terms of mechanism difference between robot and $\mathrm{CNC}$ machine tool. Given consistence issue of a tool path, Agus et al. [104] proposed a joint space path planning in robot machining. However, they have not validated the method experimentally. To optimise a feed orientation, Chen et al. [105] proposed a normal stiffness performance index which is derived from the comprehensive stiffness performance index, based on the relationship between external force and $\mathrm{EE}$, to evaluate robot stiffness on a given posture. Cutting force and cutting vibration are sensitive factors for robotic machining. Extending the conventional CAD-CAM with simulation, Brüning et al. [106] proposed a process planning chain for robots machining, in which cutting force was simulated. A further experimental work was needed to be performed to validate the method. Cen and Melkote [107] developed a milling force model combining robot dynamics and external force on robot stiffness. Via the model, their results showed that the milling forces were reduced by $50-70 \%$. Wang and Keogh [108] carried out a set of experiments to reduce robot-machining vibrations by controlling vibration associated with cutting force, and the root mean square vibration was reduced by $25 \%$. Huynh et al. [109] modelled an IR compelled to machining operation. By combining the effect of all joint flexibilities and gear backlash, the models were able to produce cutting force and machined shape in milling of aluminium, rather than in machining of steel. Cutting process, where the vibration comes from, was concerned. Cutting process was modelled together with robot stiffness, and Garnier et al. [110] combined two models to analyse the elasto-static behaviour of the robot while drilling. Tool wears were concerned as well; Tratar et al. [111] compared machining performances by IR and in CNC machine; drawing the bigger tool wear was generated in the lower rigidity configuration of robot. In addition, combining machining planning, programming and real-time control, Schreck et al. [112] reported an industrial machining robot which could provide a solution for hard material machining of small-batch and highlycustomised products. Furtado et al. [113] proposed an experiment based approach to evaluate the robot-machining aluminium workpiece. In their method, a five-step experiment was carried out to optimise robot poses, milling directions, cutting strategies and depth of cut, milling parameters, and to check the programmed velocity and configured parameters, and repeatability.

The similar factors with CNC machining should be updated and adjusted as well, cutting parameters and cutting tool. Matsuoka et al. [114] proposed a high-speed milling in which a small-diameter, $3 \mathrm{~mm}$, cutting tool and a high-speed spindle, 100,000 rpm, were two keys to reduce the cutting force. Their results showed that cutting force was reduced by $50-70 \%$ compared with using a fluting machine. In a high-speed machining category, Mejri et al. [115] observed dynamic characterisation of robotic machining system. Cutting conditions should be adaptively changed along with robot posture to ensure stability in terms of dynamic property differences, as shown in Fig. 5. Tratar and Kopač [116] applied successfully a robot to milling used to remove the welding materials by selecting proper processing parameters. Cutting tool is another important resource. Tool geometry, number of teeth, feed rate, spindle speed and properties of the material were considered by Klimchik et al. [117], and they developed a compliance error compensation for robot milling based on non-linear stiffness model which was used to optimise trajectory to avoid the machining chatter. Afterwards, tool deflection was added into the compensation model by them [118].

In summary, compared with the conventional machining performed in CNC machining tool, only some standalone research has been reported; therefore, there have been a lack of systematic research on machining process optimisation, e.g. cutting tool, machining parameters, coolant.

\subsection{Machining quality}

Machining qualities including dimensional accuracy and surface qualities are the key evaluation indexes to determine whether an IR can be used in machining or not. Dimensional accuracy is an essential requirement, and sensitive to machining system stiffness. An idea to reduce cutting force was considered by Höfener and Schüppstuhl $[119,120]$ by using a small IR in aircraft repairing of composite materials. Their experimental results showed that the IR offered some significant advantages compared to other kinds of kinematics for onaircraft milling application, and machining accuracy was increased. To identify error sources, Kothe et al. [121] proposed a performance assessment strategy, in which the actual toolposition/orientation could be calculated along with plotting the robot encoder during movement. Then, a real-time guidance with laser tracker and control parameter optimisation were combined to implement the method. Gear backlash errors in machining were compensated by an online controller developed by Kubela et al. [122]. Based on robot stiffness and reversal error, Cordes and Hintze [123] developed a path deviation predictive model in joint space. Their results showed 

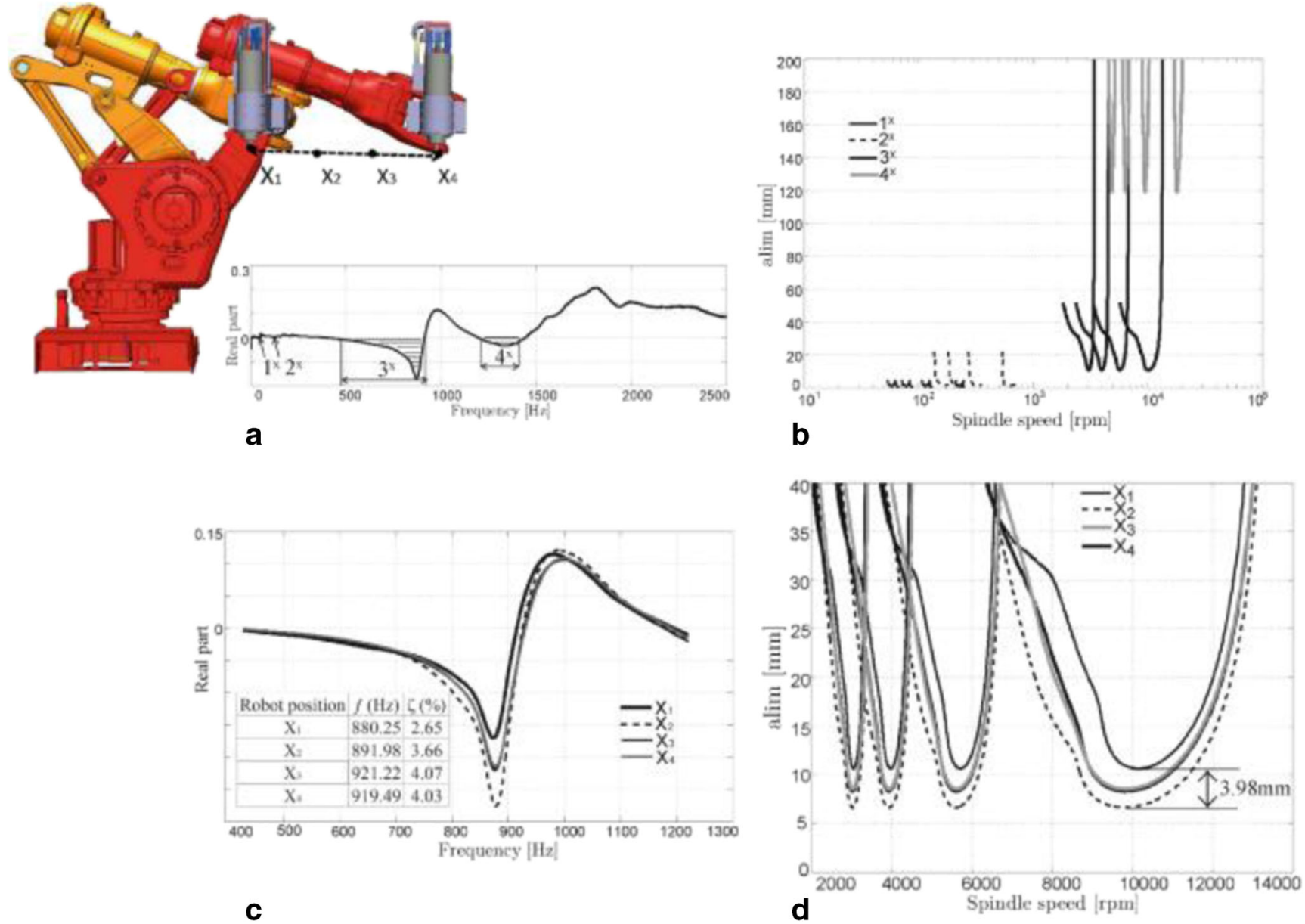

Fig. 5 Robot machining related research field [115]

that a reduction of dimension and form deviations could be archived by an offline compensation based on the proposed method. Surface quality was focused on as well. Tang et al. [124] combined robot static stiffness and cutting force model to establish the tool point deformation model. By analysing the models, the translation of tool point is the major factor to machining errors. Surface roughness was focused by Slamani et al. [125], and they compared roughness in trimming performed by high-speed CNC machine tool and a robot with a high-speed spindle. The surface roughness in robot trimming is dominated by a large trajectory deviation. Then, Slamani and Chatelain [126] identified the relevant sources of errors. They found that a strong dependence between parts accuracy, cutting direction and robot position.

Additionally, towards a performance standard, Barnfather et al. [127] compared available performance evaluation standards of both robot and machine tool, and proposed a method to deliver a robust performance evaluation of robots. Then, they proposed a photogrammetry-based metrology assistance algorithm to compensate machining errors [128]. In their method, the closest point to nominal cutting coordinates on an aligned inspection surface was used for compensation to generate a penultimate measured cut.
The machining qualities of robotic machining mainly refer to dimensional accuracy, and surface quality. Machining error source has been studied to identify the reason and solve the problem. Some performance standard has been considered to evaluate IRs. Apart from conventional machining, robotic machining should be understood systemically due to each element in the system that may cause machining quality problem.

\subsection{Monitoring and compensation}

Machining vibration is a serious issue due to there is still uncertainty in robot machining; therefore, a real-time monitoring and its compensation are the solutions. Lehmann et al. [129] proposed an approach to compensate machining errors by reducing cutting force. In their method, three steps are included; a machining strategy was generated first, based on which, a tool path was obtained and optimised to reduce force, and finally an online compensation was used based on a force/ torque sensor mounted between EE and tools including spindle and cutting tool. Denkena et al. [130] proposed a hybrid drive concept of robot to improve their machining capability. Their simulation result demonstrated that it performed well 
when torque motor working, and a potential application in machining could be improved. Based on robot force control and programming method, Domrös et al. [131] proposed an autonomous robot-machining concept, where the feed speed could be changed along with tool path accordingly. Xie et al. [132] proposed a force control robotic mill method in which a force sensor was mounted between $\mathrm{EE}$ and spindle. In their method, there is no experiment to be done to validate the method yet. Machining error identification can help to compensate machining error. Posada et al. [133] analysed the error sources in robot-machining process, and proposed an external sensor based approach to reduce the machining error, of which a drill experiment showed that it delivered a better performance compared with a compliance model-based compensation. Qin et al. [134] developed a robot drilling system, in which two accelerometer sensors were used to obtain the vibration signals of the EE which was analysed to calculate the location and orientation errors. Rosa et al. [135] developed a force control strategy to enhance the application possibility of robot drilling. The method was used to improve drilling quality by assuring the thrust force, and to reduce the sliding during the first contact between the twist drill and the workpiece. Brunete et al. [136] proposed hard materials machining by robot with an improved position-control approach and enhanced compliance-control functions. In their method, a novel strategy to compensate for elastic could improve the robot performance and applicability of robots in machining tasks.

So far, the machining quality is still difficult to be guaranteed due to there are many factors causing uncertain force and vibrations. Therefore, an on-line sensor monitoring can be used to detect the uncertain condition, and a compensation can improve machining accuracy based on research on machining source identification of robotic machining.

\subsection{Other aspects}

Apart from machining quality-related research, many other aspects were reported as well, e.g. calibration, STEP-NC, simulator and energy efficiency. Leali et al. [137] designed a twostep calibration method to improve the accuracy of robot milling, including a first calibration of the workpiece-independent equipment in the workcell layout and a final automated online calibration of workpiece-dependent equipment. STEP-NC was proposed to use in robot machining [138], and a similar concept was also proposed and tested [139]. Rea Minango and Ferreira [140] combined STEP-NC and forward/inverse kinematics methods to generation tool path for robot. Zivanovic et al. [141] and Toquica et al. [142] developed a RoboSTEP$\mathrm{NC}$ module for robotic machining, in which STEP-NC was implemented. A virtual robot-machining simulator was developed by Huynh et al. [143], and it was used to optimise the cutting parameters in robot milling. Afterwards, they updated a set of modal analysis, in which both identified natural frequencies and damping ratios were used to update an elastodynamic model of the robot through a minimisation procedure [144]. Energy efficiency was given an attention by Uhlmann et al. [145], and they identified the energy status which provides energy-optimised path planning in CAM system of robot machining. In addition, Denkena et al. [146] discussed the needed changes of the conventional process planning chain to adapt robotic machining. A remote robot-machining concept via Internet was presented for robot machining by Lee et al. [147]. Special robot structure, a hexapod robot, was designed for robot machining by Choi et al. [148].

\section{Recap on technologies of robotic machining}

\subsection{Low-MRR operations}

High flexibility and high robustness are the trends of robotic machining for low-MRR operations, requiring a lot of hardware and software working together. Therefore, integration technology plays a key role in terms of stability, extensibility and compatibility of robotic machining systems. Towards the solution, two directions are the keys:

- A well-structured communication framework: it should provide a well-structured interface, and allow fluent communication between models, hardware and software with a certain robust. Also, it could be extended easily when new models are added.

- A well-modelled manufacturing process: manufacturing processes should be distributed into the detailed models which could be developed and enhanced separately. In the models, input and output are well defined.

There are still many real-world scenarios in which human operators perform tasks on a shop floor. For example, additional grinding work is generally carried out to smooth the surface on car body die after finish machining, and similarly, deburring and polishing of nuclear reactor parts are needed after finish machining (https://www.coroma-project.eu/). By overcoming the problems above, robotic machining can be applied in the cases,

\subsection{High-MRR operations}

The applicability of robotic machining in high-MRR operations is still called into question in terms of machining stability and machining quality, machining repeatability/stability. However, the potential benefit from robot machining makes it worth to be discussed further. The major problem of robotic machining comes from robot stiffness and machining vibration which are corresponding to low-stiffness IR and machining process. From 
Fig. 6 Research topics for highMRR operations

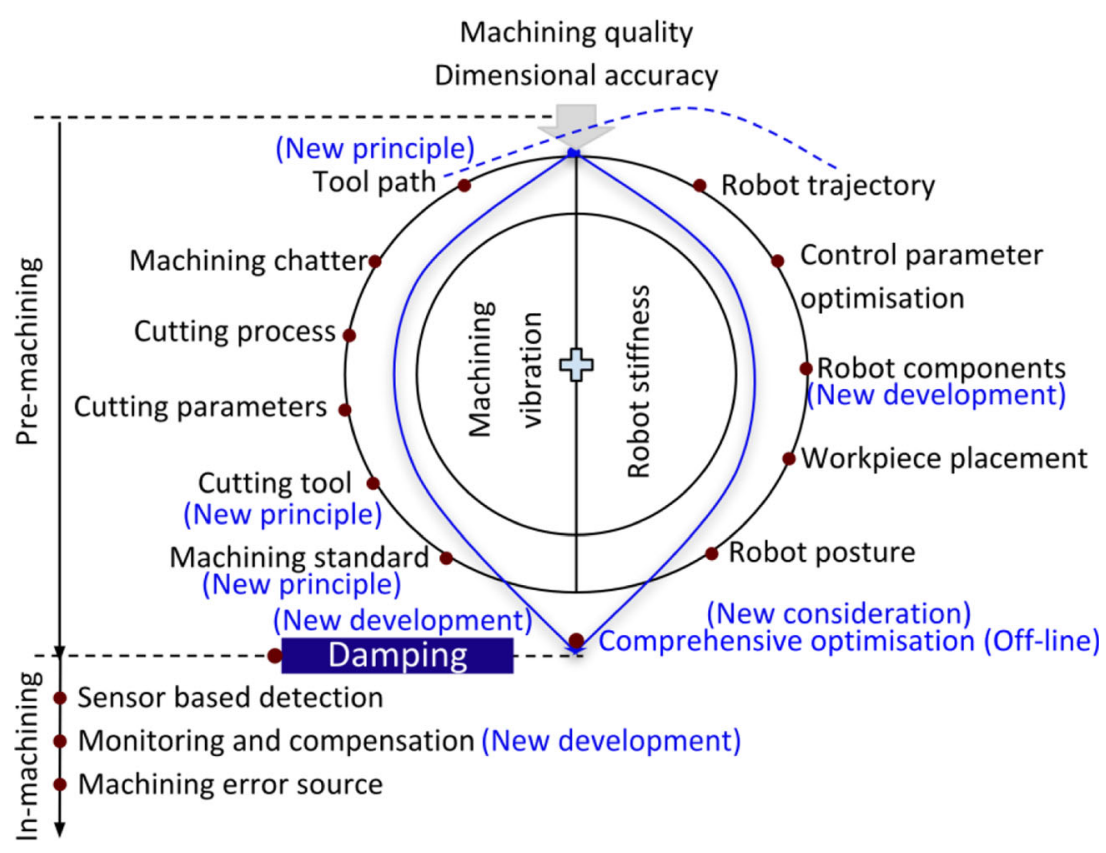

the reported publications, as shown in Fig. 6, robot stiffness research involves control parameter optimisation, robot components, workpiece placement, robot posture and robot trajectory, etc. Whereas, the machining processes refer to tool path, chatter, cutting process, cutting tool, and machining standard, etc. To suppress the vibration, damping, sensor-based detection, and real-time monitoring have been touched, and to compensate the errors, and machining error sources have also identified. Many major points could be improved to robotic machining in terms of new developments, new principles and new consideration from short-term to long-term improvement.

\subsubsection{Robot components and damping devices}

Originally, IR was not designed for machining application; therefore, less research was focused on improving the components. A set of well components could provide a great enhancement of robot stiffness. In the near future, smart damping device by which the vibrations could be suppressed will be still a solution for robotic machining. With their help, machining qualities could be improved and acceptable for the real applications.

\subsubsection{Real-time monitoring and compensation}

The stability of robotic machining generates uncertainties on a shop floor before the robotic machining behaviour is completely understood. In general, the uncertainties cannot be avoided by off-line optimisation. Therefore, a real-time monitoring system is necessary to handle such manufacturing environment to caption the unusual conditions, together with a proper error compensation algorithm.

\subsubsection{Updating principles}

Nowadays, the research on robotic machining is based on the conventional machining principles and evaluation system; as a result, it is very different to archive acceptable machining quality. A cutting tool design, for example, is designed to deliver a high tool life, rather than a low cutting force. However, the cutting force has the priority. Therefore, towards an applicable robotic machining, the design principles on cutting area should be updated accordingly.

\subsubsection{Comprehensive optimisation of robotic machining}

The conventional CNC machine tool is stiff enough for material removing, which allows the related research to be carried out separately, e.g. materials cutting, machine tool design, cutting tool design and cutting condition optimisation. However, IR is not as stiff as CNC machine, so that cutting process with high cutting forces and high-frequency vibration weakens the effect of each individual research. In this case, optimisation of each individual part cannot solve the problem totally. Therefore, optimisation of the entire robotic machining system should be treated as one problem, in case of which a globe optimisation could be archived as a long-term improvement of robotic machining. A machine learning associated with big data is able to provide a comprehensive parametric optimisation, which is a potential solution.

Many machining scenarios in shop floors could be performance potentially. For example, many assembly-orientated holes and surfaces are needed to be machined on site to guarantee that the relevant parts can be assembled. Such as, face 
milling of assembly interfaces and drilling of connection holes are needed to be milled on site to dock tail on fuselage [149].

\subsection{A statistical analysis}

There are 122 published papers from 1987 to 2018, including 64 conference papers, 55 journal papers and 4 books/theses. Within journals, Robotics and Computer-Integrated Manufacturing and International Journal of Advanced manufacturing Technology are the two major journals publishing robot-machining research, and include 16 (26.67\% in journal papers) and 11 (21.67\% in journal papers) publications, respectively. In addition, there are other journals publishing more than one, i.e. Measurement (2), Journal of Material Processing Technology (2), International Journal of Computer Integrated Manufacturing (2), Industrial Robot: An International Journal (2), Production Engineering (2), Technique (2) and Journal of Manufacturing Processes (2). Figure 7 shows the total number of robotic machining research publications from 1987 to 2018. The publications are less than six per year before 2013, and then they were increased from 2013, and 98 papers (75.97\% in publications) were reported.

There are 23 countries/areas of the authors who published the robotic machining works, as shown in Fig. 8. Here, there are four countries having more than 10 publications, where Germany (24.03\%), China (20.16\%), France (10.85\%) and Canada $(8.53 \%)$. In addition, there are four countries of which percentiles are higher than $3 \%$, i.e. UK (3.86\%), Italy (3.86\%), Japan (3.10\%) and Brazil (3.10\%).

\section{Conclusions}

The paper reviews the research publications of robotic machining, and by considering the difference of research topics, classifies robotic machining into low-MRR operations (including grinding, polishing and deburring) and high-MRR operations (involving milling and drilling). Then, the previous review papers are gone through, together with research topics of robotic machining, in which, robotic machining dynamics, robotic machining configurations, trajectory optimisation,

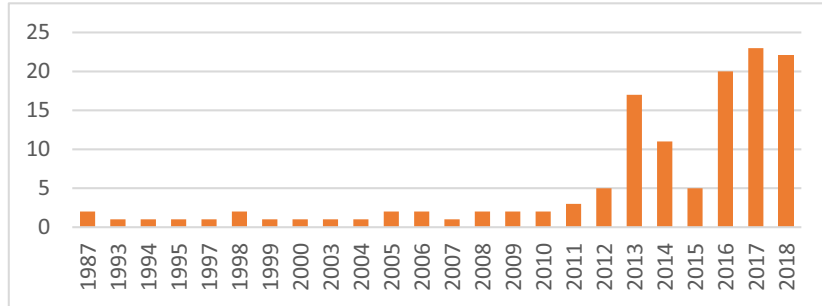

The data collection before 01 January 2019

Fig. 7 Total number of robotic machining publications from 1987 to 2018

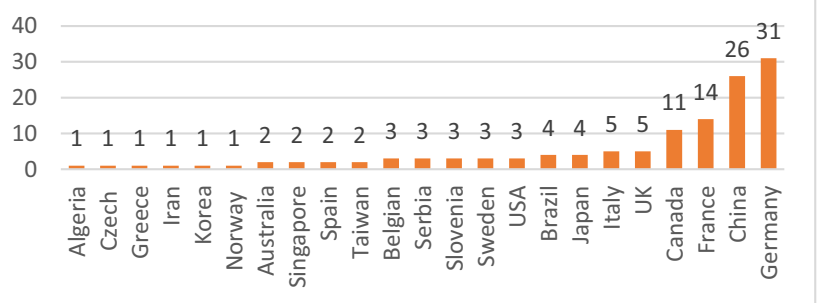

Fig. 8 Countries and areas of authors publishing most robotic machining works

machining processes, machining quality, monitoring and compensation and other aspects. Finally, a recap on robotic machining is given, together with a statistical analysis carried out in terms of published journal, years and countries. The major found trends are summarised as follows:

- In low-MRR operations, the study of robotic machining started from sensor-based human-like operation, then an improved machining quality compared to human operators, and targeted a flexible scenario in which human and IR work together closely; therefore, IRs, sensors and software modules should be organised in a proper way.

- Whereas, for high-MRR operations, towards an alternative of partial CNC machines, almost all of reported publications aim to enhance stiffness and to suppress machining vibration. Some robotic machining configurations improve machining quality by reducing the flexibility. Then, robot trajectory, machining process and quality have been considered. Real-time monitoring and compensation have been focused on to improve machining accuracy. However, there is still no reported work to guarantee a stable and high-machining quality.

- The research on robotic machining was increased since 2013, and more than $75 \%$ publications were published, and most of authors $(63.57 \%)$ are from German, China, France and Canada. Also, the publications will be increased significantly in the following years.

There are several potential directions of future research which could make the robotic machining to be applied in real industries, according to the observed trends and distance between real application and research. Robotic machining configurations, damping technologies and 3.7 monitoring and compensation are the straightforward ways to improve machining quality and accuracy based on the current manufacturing environment and structure, as the short-time developments. However, from the long-time development, point-ofview, the potential research should be planned as follows:

- A flexible and robust system is a key for low-MRR operations in the future industrial applications to deliver a safe and stable working environment in which human operators are allowed to work together with IRs. That requires a 
well integration technology in teams of software and manufacturing.

- A comprehensive optimisation should be performed for robotic machining system in teams of robot stiffness and machining vibration, including all relevant elements, e.g. IRs, robot motion, robot control, workpiece and its placement, tool path, cutting tool, cutting conditions and other aspects. Here, machine learning associated with big data will be one of the solutions with the data benefit to improve high-MRR robot-machining stability, which requires data representation and robot-machining digitalisation.

- An update of the relevant machining principles in conventional machining environment is needed for high-MRR operations by considering the properties of robotic machining system. For example, both machining quality and tool life have been the major objectives for cutting design in conventional manufacturing; however, in robotic machining, the major objective should be the low cutting force and low cutting vibration which generate a good machining quality.

Acknowledgements This work is supported by an EU project, COROMA: Cognitively Enhanced Robot for Flexible Manufacturing of Metal and Composite parts (H2020-IND-CE-2016-17).

Open Access This article is distributed under the terms of the Creative Commons Attribution 4.0 International License (http:// creativecommons.org/licenses/by/4.0/), which permits unrestricted use, distribution, and reproduction in any medium, provided you give appropriate credit to the original author(s) and the source, provide a link to the Creative Commons license, and indicate if changes were made.

\section{References}

1. Cheng K (2008) Machining dynamics: fundamentals, applications and practices. Springer Science \& Business Media

2. Altintas Y (2012) Manufacturing automation: metal cutting mechanics, machine tool vibrations, and $\mathrm{CNC}$ design. Cambridge university press

3. International Federation of Robotics I (2017) Executive summary world Robotics 2017 Industrial Robots

4. Appleton E, Williams DJ (1987) Industrial robot applications. HALSTED PRESS, New York

5. Hu YN, Chen YH (1999) Implementation of a robot system for sculptured surface cutting. Part 2. Finish machining. Int J Adv Manuf Technol 15:630-639. https://doi.org/10.1007/ s001700050112

6. Song Y, Chen YH (1999) Feature-based robot machining for rapid prototyping. Proc Inst Mech Eng Part B J Eng Manuf 213:451459. https://doi.org/10.1243/0954405991516921

7. Milutinovic D, Glavonjic M, Slavkovic N, Dimic Z, Zivanovic S, Kokotovic B, Tanovic L (2011) Reconfigurable robotic machining system controlled and programmed in a machine tool manner. Int $\mathrm{J}$ Adv Manuf Technol 53:1217-1229. https://doi.org/10.1007/ s00170-010-2888-8

8. Dimic Z, Milutinovic D, Zivanovic S, Kvrgic V (2016) Virtual environment in control and programming system for reconfigurable machining robot 9 . Teh Vjesn - Tech Gaz 23: 1821-1182. https://doi.org/10.17559/TV-20150210133556

9. Nagata F, Otsuka A, Watanabe K, Habib MK (2014) Fuzzy feed rate controller for a machining robot. IEEE Int Conf Mechatronics Autom IEEE ICMA 2014:198-203. https://doi.org/10.1109/ ICMA.2014.6885695

10. Nagata F, Otsuka A, Watanabe K, Habib MK (2015) Machining robot for foamed polystyrene materials using fuzzy feed rate controller Fusaomi Nagata * and Akimasa Otsuka Keigo Watanabe. Int J Mechatronics Autom 5:34-43

11. Nagata F, Habib MK, Otsuka A, Hayashi S, Nagatomi T, Watanabe K (2015) Vibrational motion control for foamed polystyrene machining robot and extraction of radius of curvature for fuzzy feed rate control. Artif Life Robot 20:197-202. https://doi. org/10.1007/s10015-015-0221-1

12. Nagata F, Hayashi S, Nagatomi T, et al (2015) Robotic trajectory following controller with a capability for generating micro vibrational motion along curved surface. IECON 2015 - 41st Annu Conf IEEE Ind Electron Soc 765-770. doi: https://doi.org/10. 1109/IECON.2015.7392191

13. Nagata F, Watanabe K, Habib MK (2018) Machining robot with vibrational motion and 3D printer-like data interface. Int J Autom Comput 15:1-12. https://doi.org/10.1007/s11633-017-1101-z

14. Vergeest JSM, Tangelder JWH (1996) Robot machines rapid prototype. Ind Robot An Int J 23:17-20. https://doi.org/10.1108/ 01439919610130328

15. Pandremenos J, Doukas C, Stavropoulos P, Chryssolouris G (2011) Machining with robots: a critical review. 7th Int Conf Digit Enterp Technol

16. Chen Y, Dong F (2013) Robot machining: recent development and future research issues. Int J Adv Manuf Technol 66:1489-1497. https://doi.org/10.1007/s00170-012-4433-4

17. Karim A, Verl A (2013) Challenges and obstacles in robot-machining. 2013 44th Int Symp robot ISR 2013. doi: https://doi.org/ 10.1109/ISR.2013.6695731

18. Bo H, Azhar M, Mohan DM, Campolo D (2015) Review of robotic control strategies for industrial finishing operations. In: 2015 10th International Symposium on Mechatronics and its Applications (ISMA). pp 1-6

19. Iglesias I, Sebastián MA, Ares JE (2015) Overview of the state of robotic machining: current situation and future potential. Procedia Eng 132:911-917. https://doi.org/10.1016/j.proeng.2015.12.577

20. Yuan L, Pan Z, Ding D, Sun S, Li W (2018) A review on chatter in robotic machining process regarding both regenerative and mode coupling mechanism. IEEE/ASME Trans Mechatronics 23:2240-2251. https://doi.org/10.1109/ TMECH.2018.2864652

21. Izumi T, Narikiyo T, Fukui Y (1987) Teachingless grinding robot depending on three force information. Adv Robot 2:55-67

22. Muto S, Shimokura K (1994) Teaching and control of robot contour-tracking using contact point detection. Proc 1994 IEEE Int Conf Robot Autom:674-681. https://doi.org/10.1109/ ROBOT.1994.351408

23. Jinno M, Ozaki F, Yoshimi T et al (1995) Development of a force controlled robot for grinding, chamfering and polishing. Proc IEEE Int Conf Robot Autom 2:1455-1460. https://doi.org/10. 1109/ROBOT.1995.525481

24. Surdilovic D, Zhao H, Schreck G, Krueger J (2012) Advanced methods for small batch robotic machining of hard materials. Robot Proc Robot 2012; 7th Ger Conf 1-6

25. Villagrossi E, Pedrocchi N, Beschi M, Molinari Tosatti L (2018) A human mimicking control strategy for robotic deburring of hard materials. Int J Comput Integr Manuf 31:869-880. https://doi.org/ 10.1080/0951192X.2018.1447688 
26. Domroes F, Krewet C, Kuhlenkoetter B (2013) Application and analysis of force control strategies to deburring and grinding. Mod Mech Eng 3:11-18. https://doi.org/10.4236/mme.2013.32A002

27. Chen F, Zhao H, Li D, Chen L, Tan C, Ding H (2018) Robotic grinding of a blisk with two degrees of freedom contact force control. Int J Adv Manuf Technol. https://doi.org/10.1007/ s00170-018-2925-6

28. Ding Y, Min X, Fu W, Liang Z (2018) Research and application on force control of industrial robot polishing concave curved surfaces. Proc Inst Mech Eng Part B J Eng Manuf 0954405418802309. doi: https://doi.org/10.1177/ 0954405418802309

29. Leali F, Pellicciari M, Pini F, Berselli G, Vergnano A (2013) An offline programming method for the robotic deburring of aerospace components. In: Neto P, Moreira AP (eds) Robotics in Smart Manufacturing. Springer Berlin Heidelberg, Berlin, Heidelberg, pp 1-13

30. Rafieian F, Hazel B, Liu Z (2014) Regenerative instability of impact-cutting material removal in the grinding process performed by a flexible robot arm. Procedia CIRP 14:406-411. https://doi. org/10.1016/j.procir.2014.03.099

31. Liu H, Wan Y, Zeng Z, et al (2016) Freeform surface grinding and polishing by CCOS based on industrial robot. In: 8th International Symposium on Advanced Optical Manufacturing and Testing Technologies: Advanced Optical Manufacturing Technologies,

32. Xie S, Li S, Chen B, Qi J (2017) Research on robot grinding technology considering removal rate and roughness. In: Huang Y, Wu H, Liu H, Yin Z (eds) Intelligent robotics and applications. Springer International Publishing, Cham, pp 79-90

33. Sufian M, Chen X, Yu D (2017) Investigating the capability of precision in robotic grinding. In: Proceedings of the $23 \mathrm{rd}$ International Conference on Automation \& Computing. Huddersfield, UK

34. Li W, Xie H, Zhang G, Yan SJ, Yin ZP (2016) 3-D shape matching of a blade surface in robotic grinding applications. IEEE/ASME Trans Mechatronics 21:2294-2306

35. Mao Y, Zhao H, Zhao X, Ding H (2017) Trajectory and force generation with multi-constraints for robotic belt grinding. In: Huang Y, Wu H, Liu H, Yin Z (eds) Intelligent robotics and applications. Springer International Publishing, Cham, pp 14-23

36. Zhang T, Su J (2018) Collision-free planning algorithm of motion path for the robot belt grinding system. Int J Adv Robot Syst 15: 172988141879377. https://doi.org/10.1177/1729881418793778

37. Yan S, Xu X, Yang Z, Zhu D, Ding H (2019) An improved robotic abrasive belt grinding force model considering the effects of cut-in and cut-off. J Manuf Process 37:496-508. https://doi.org/10.1016/ j.jmapro.2018.12.029

38. Pandian J (1998) Automated fixture and robot aided deburring for light aircraft components. University of Manitoba, Winnipeg, Manitoba

39. Huang H, Gong ZM, Chen XQ, Zhou L (2003) SMART robotic system for $3 \mathrm{D}$ profile turbine vane airfoil repair. Int J Adv Manuf Technol 21:275-283. https://doi.org/10.1007/ s001700300032

40. Ricardo J, Posada D, Kumar S, et al (2016) Automatic programming and control for robotic deburring description of the robot deburring system. In: 47th international symposium on Robotics pp 688-695

41. Ji W, Wang Y, Liu H, Wang L (2018) Interface architecture design for minimum programming in human-robot collaboration. Procedia CIRP 72:129-134. https://doi.org/10.1016/j.procir. 2018.03.013

42. Ji W, Li Y, Wang L (2018) A task-oriented cyber-physical system in manufacturing. In: The 48th international conference on computers and industrial engineering. Auckland, p 8
43. Diao S, Chen X, Luo J (2018) Development and experimental evaluation of a 3D vision system for grinding robot. Sensors (Switzerland) 18:1-20. https://doi.org/10.3390/s18093078

44. KATIC D, VUKOBRATOVIC M (1997) Classification and learning of robot-environment dynamic models. In: proceedings of the 1997 EEE Intemational conference on robotics and automation. pp 2632-2637

45. Katić D, Vukobratović M (1998) A neural network-based classification of environment dynamics models for compliant control of manipulation robots. IEEE Trans Syst Man, Cybern Part B Cybern 28:58-69. https://doi.org/10.1109/3477.658578

46. Zhang H, Wang J, Zhang G, et al (2005) Machining with flexible manipulator: toward improving robotic machining performance. Proceedings, 2005 IEEE/ASME Int Conf Adv Intell Mechatronics 1127-1132 . doi: https://doi.org/10.1109/AIM.2005.1511161

47. Dumas C, Caro S, Garnier S, Furet B (2011) Joint stiffness identification of six-revolute industrial serial robots. Robot Comput Integr Manuf 27:881-888. https://doi.org/10.1016/j.rcim.2011. 02.003

48. Denkena B, Bergmann B, Lepper T (2017) Design and optimization of a machining robot. In: Procedia Manufacturing. Elsevier B.V., pp 89-96

49. Caro S, Dumas C, Garnier S, Furet B (2013) Workpiece placement optimization for machining operations with a KUKA KR270-2 robot. Proc - IEEE Int Conf Robot Autom 2921-2926 . doi: https://doi.org/10.1109/ICRA.2013.6630982

50. Caro S, Dumas C, Garnier S, Furet B (2013) Workpiece placement optimization in robotic-based manufacturing. IFAC, Workpiece Placement Optimization in Robotic-based Manufacturing

51. Caro S, Garnier S, Furet B, et al (2014) Workpiece placement optimization for machining operations with industrial robots. IEEE/ASME Int Conf Adv Intell Mechatronics, AIM 17161721. doi: https://doi.org/10.1109/AIM.2014.6878331

52. Garnier S, Dumas C, Caro S, Furet B (2013) Quality certification and productivity optimization in robotic-based manufacturing. IFAC, Quality Certification and Productivity Optimization in Robotic-based Manufacturing

53. Klimchik A, Ambiehl A, Garnier S, Furet B, Pashkevich A (2016) Experimental study of robotic-based machining. IFACPapersOnLine 49:174-179. https://doi.org/10.1016/j.ifacol.2016. 07.591

54. Klimchik A, Ambiehl A, Garnier SS, Furet B, Pashkevich A (2017) Efficiency evaluation of robots in machining applications using industrial performance measure. Robot Comput Integr Manuf 48:12-29. https://doi.org/10.1016/j.rcim.2016.12.005

55. Subrin K, Sabourin L, Gogu G, Mezouar Y (2012) Performance criteria to evaluate a kinematically redundant robotic cell for machining tasks. Appl Mech Mater 162:413-422. https://doi.org/10. 4028/www.scientific.net/AMM.162.413

56. Lin Y, Zhao H, Ding H (2017) Posture optimization methodology of $6 \mathrm{R}$ industrial robots for machining using performance evaluation indexes. Robot Comput Integr Manuf 48:59-72. https://doi. org/10.1016/j.rcim.2017.02.002

57. Xiong G, Ding Y, Zhu LM (2019) Stiffness-based pose optimization of an industrial robot for five-axis milling. Robot Comput Integr Manuf 55:19-28. https://doi.org/10.1016/j.rcim.2018.07. 001

58. Xie H, Li W, Yin Z (2018) Posture Optimization Based on Both Joint Parameter Error and Stiffness for Robotic Milling. In: Chen Z, Mendes A, Yan Y, Chen S (eds) Intelligent robotics and applications. Springer International Publishing, Cham, pp 277-286

59. Mousavi S, Gagnol V, Bouzgarrou BC, Ray P (2017) Dynamic modeling and stability prediction in robotic machining. Int $\mathrm{J} \mathrm{Adv}$ Manuf Technol 88:3053-3065. https://doi.org/10.1007/s00170016-8938-0 
60. Mousavi S, Gagnol V, Bouzgarrou BC, Ray P (2018) Stability optimization in robotic milling through the control of functional redundancies. Robot Comput Integr Manuf 50:181-192. https:// doi.org/10.1016/j.rcim.2017.09.004

61. Karim A, Hitzer J, Lechler A, Verl A (2017) Analysis of the dynamic behavior of a six-axis industrial robot within the entire workspace in respect of machining tasks. IEEE/ASME Int Conf Adv Intell Mechatronics, AIM:670-675. https://doi.org/10.1109/ AIM.2017.8014094

62. Bu Y, Liao W, Tian W, Zhang J, Zhang L (2017) Stiffness analysis and optimization in robotic drilling application. Precis Eng 49: 388-400. https://doi.org/10.1016/j.precisioneng.2017.04.001

63. Pan ZZ, Zhang H, Zhu Z, Wang J (2006) Chatter analysis of robotic machining process. J Mater Process Technol 173:301309. https://doi.org/10.1016/j.jmatprotec.2005.11.033

64. Abele E, Weigold M, Rothenbücher S (2007) Modeling and identification of an industrial robot for machining applications. CIRP Ann - Manuf Technol 56:387-390. https://doi.org/10.1016/j.cirp. 2007.05.090

65. Cordes M, Hintze W, Altintas Y (2019) Chatter stability in robotic milling. Robot Comput Integr Manuf 55:11-18. https://doi.org/10. 1016/j.rcim.2018.07.004

66. Safi SM, Amirabadi H, Lirabi I, Khalili K, Rahnama S (2013) A new approach for chatter prediction in robotic milling based on signal processing in time domain. Appl Mech Mater 346:45-51. https://doi.org/10.4028/www.scientific.net/AMM.346.45

67. Vieler H, Karim A, Lechler A (2017) Drive based damping for robots with secondary encoders. Robot Comput Integr Manuf 47: 117-122. https://doi.org/10.1016/j.rcim.2017.03.007

68. Yuan L, Sun S, Pan Z, Ding D, Gienke O, Li W (2019) Mode coupling chatter suppression for robotic machining using semiactive magnetorheological elastomers absorber. Mech Syst Signal Process 117:221-237. https://doi.org/10.1016/j.ymssp. 2018.07.051

69. Yuan L (2017) A study of chatter in robotic machining and a semiactive chatter suppression method using magnetorheological elastomers (MREs). University of Wollongong

70. Puzik A, Meyer C, Verl A (2010) Industrial robots for machining processes in combination with a 3D-piezo-compensation mechanism. CIRP Intell Comput Manuf Eng ICME

71. Guo Y, Dong H, Wang G, Ke Y (2016) Vibration analysis and suppression in robotic boring process. Int $\mathrm{J}$ Mach Tools Manuf 101:102-110. https://doi.org/10.1016/j.ijmachtools.2015.11.011

72. Puzik A, Meyer C, Verl A (2010) Results of robot machining with additional 3D-piezo-actuation-mechanism for error compensation.7th CIRP Int Conf, Intell Comput ... 415-421

73. Olofsson B, Sörnmo O, Schneider U, et al (2011) Modeling and control of a piezo-actuated high-dynamic compensation mechanism for industrial robots. In: 2011 IEEE/RSJ international conference on intelligent robots and systems. pp 4704-4709

74. Lehmann C, Pellicciari M, Drust M, Gunnink JW (2013) Machining with industrial robots: the COMET project approach. In: Neto P, Moreira AP (eds) Robotics in smart manufacturing. Springer Berlin Heidelberg, Berlin, Heidelberg, pp 27-36

75. Schneider U, Ansaloni M, Drust M, Leali F, Verl A (2013) Experimental investigation of sources of error in robot machining. In: Neto P, Moreira AP (eds) Robotics in smart manufacturing. Springer Berlin Heidelberg, Berlin, Heidelberg, pp 14-26

76. Schneider U, Drust M, Puzik A, Verl A (2013) Compensation of errors in robot machining with a parallel 3D-piezo compensation mechanism. Procedia CIRP 7:305-310. https://doi.org/10.1016/j. procir.2013.05.052

77. Olof S, Schneider U, Robertsson A, et al (2013) High-accuracy milling with industrial robots using a piezo-actuated high-dynamic compensation mechanism. Comet
78. Schneider U, Momeni-K M, Ansaloni M, Verl A (2014) Stiffness modeling of industrial robots for deformation compensation in machining. IEEE Int Conf Intell Robot Syst 4464-4469 . doi: https://doi.org/10.1109/IROS.2014.6943194

79. Schneider U, Drust M, Ansaloni M, Lehmann C, Pellicciari M, Leali F, Gunnink JW, Verl A (2016) Improving robotic machining accuracy through experimental error investigation and modular compensation. Int J Adv Manuf Technol 85:3-15. https://doi. org/10.1007/s00170-014-6021-2

80. Haage M, Halbauer M, Lehmann C, Städter JP (2014) Increasing robotic machining accuracy using offline compensation based on joint-motion SIMULATION Proc Jt Conf ISR 2014 - 45th Int Symp Robot Robot 2014 - 8th Ger Conf Robot ISR/ROBOTIK 2014 347-354

81. Schneider U, Diaz Posada JR, Verl A (2015) Automatic pose optimization for robotic processes. Proc - IEEE Int Conf robot autom 2054-2059. doi: https://doi.org/10.1109/ICRA.2015. 7139468

82. Halbauer M, Lehmann C, Städter JP et al (2013) Milling strategies optimized for industrial robots to machine hard materials. IEEE Int Conf Emerg Technol Fact Autom ETFA:1-4. https://doi.org/10. 1109/ETFA.2013.6648124

83. Leali F, Pini F, Ansaloni M (2013) Integration of CAM off-line programming in robot high-accuracy machining. In: proceedings of the 2013 IEEE/SICE international symposium on system Integration pp 580-585

84. Wang G, Dong H, Guo Y, Ke Y (2016) Dynamic cutting force modeling and experimental study of industrial robotic boring. Int J Adv Manuf Technol 86:179-190. https://doi.org/10.1007/s00170015-8166-Z

85. Wang G, Dong H, Guo Y, Ke Y (2017) Chatter mechanism and stability analysis of robotic boring. Int J Adv Manuf Technol 91: 411-421. https://doi.org/10.1007/s00170-016-9731-9

86. Guo Y, Dong H, Wang G (2018) A robotic boring system for intersection holes in aircraft assembly. Ind Robot An Int J 45: 328-336. https://doi.org/10.1108/IR-09-2017-0176

87. Dong S, Zheng K, Liao W (2018) Stability of lateral vibration in robotic rotary ultrasonic drilling. Int J Mech Sci 145:346-352. https://doi.org/10.1016/j.ijmecsci.2018.07.004

88. Dong S, Liao W, Zheng K, Liu J, Feng J (2019) Investigation on exit burr in robotic rotary ultrasonic drilling of CFRP/aluminum stacks. Int J Mech Sci 151:868-876. https://doi.org/10.1016/j. ijmecsci.2018.12.039

89. Huan J (1982) Bahnregelung zur Bahnerzeugung an numerisch gesteuerten Werkzeugrnaschinen. Un- iversity of Stuttgart

90. Chin JH, Tsai HC (1993) A path algorithm for robotic machining. Robot Comput Integr Manuf 10:185-198. https://doi.org/10.1016/ 0736-5845(93)90054-N

91. Krži P, Pušavec F, Kopa J (2013) Kinematic constraints and offline programming in robotic machining. Teh Vjesn 3651:117-124

92. Slamani M, Gauthier S, Chatelain JF (2014) Analysis of trajectory deviation during high speed robotic trimming of carbon-fiber reinforced polymers. Robot Comput Integr Manuf 30:546-555. https://doi.org/10.1016/j.rcim.2014.03.007

93. Slamani M, Gauthier S, Chatelain JF (2015) A study of the combined effects of machining parameters on cutting force components during high speed robotic trimming of CFRPs. Measurement 59:268-283. https://doi.org/10.1016/j. measurement.2014.09.052

94. Xiong G, Ding Y, Zhu L (2017) A feed-direction stiffness based trajectory optimization method for a milling robot. In: Huang Y, $\mathrm{Wu} \mathrm{H}$, Liu H, Yin Z (eds) Intelligent robotics and applications. Springer International Publishing, Cham, pp 184-195

95. Villagrossi E (2016) robot dynamics modelling and control for machining applications. Università degli Studi di Brescia 
96. He F, Liu Y, Liu K (2018) A chatter-free path optimization algorithm based on stiffness orientation method for robotic milling. Int J Adv Manuf Technol doi: https://doi.org/10.1007/s00170-0183099-y

97. Owen WS, Croft EA, Benhabib B (2006) Real-time trajectory resolution for a two-manipulator machining system. J Robot Syst 22:51-63. https://doi.org/10.1002/rob.20151

98. Owen WS, Croft EA, Benhabib B (2005) Acceleration and torque redistrubution for a dual-manipulator system. IEEE Trans Robot 21:1226-1230

99. Owen WS, Croft EA, Benhabib B (2004) Real-time trajectory resolution for dual robot machining. IEEE Int Conf Robot Autom 2004 Proceedings ICRA 5:4332-4337. https://doi.org/10. 1109/ROBOT.2004.1302399

100. Owen W, Croft E, Benhabib B (2008) Stiffness optimization for two-armed robotic sculpting. Ind Robot An Int J 35:46-57. https:// doi.org/10.1108/01439910810843289

101. Owen WS, Croft EA, Benhabib B (2008) A multi-arm robotic system for optimal sculpting. Robot Comput Integr Manuf 24: 92-104. https://doi.org/10.1016/j.rcim.2006.08.001

102. Owen WS, Croft EA, Benhabib B (2009) On-line trajectory resolution for two-armed systems with conflicting performance criteria. Mech Mach Theory 44:949-965. https://doi.org/10. 1016/j.mechmachtheory.2008.06.001

103. Ji W, Yin S, Wang L (2018) A big data analytics based machining optimisation approach. J Intell Manuf. https://doi.org/10.1007/ s10845-018-1440-9

104. Atmosudiro A, Keinert M, Karim A, et al (2014) Productivity increase through joint space path planning for robot machining. Proc - UKSim-AMSS 8th Eur model Symp Comput model simulation, EMS 2014 257-262 . doi: https://doi.org/10.1109/EMS. 2014.46

105. Chen C, Peng F, Yan R, Li Y, Wei D, Fan Z, Tang X, Zhu Z (2019) Stiffness performance index based posture and feed orientation optimization in robotic milling process. Robot Comput Integr Manuf 55:29-40. https://doi.org/10.1016/j.rcim.2018.07.003

106. Brüning J, Denkena B, Dittrich MA, Park H-S (2016) Simulation based planning of machining processes with industrial robots. Procedia Manuf 6:17-24. https://doi.org/10.1016/j.promfg.2016. 11.003

107. Cen L, Melkote SN (2017) Effect of robot dynamics on the machining forces in robotic milling. Procedia Manuf 10:486-496. https://doi.org/10.1016/j.promfg.2017.07.034

108. Wang Z, Keogh P (2017) Active vibration control for robotic machining. In: ASME 2017 International Mechanical Engineering Congress and Exposition

109. Huynh HN, Riviere-Lorphevre E, Verlinden O (2018) Multibody modelling of a flexible 6-axis robot dedicated to robotic machining. In: the 5 th joint international conference on multibody system Dynamics. pp 1-18

110. Garnier S, Subrin K, Waiyagan K (2017) Modelling of robotic drilling. Procedia CIRP 58:416-421. https://doi.org/10.1016/j. procir.2017.03.246

111. Tratar J, Pušavec F, Kopač J (2014) Tool wear performance evaluation in MDF machining with anthropomorphic robot. Tech Gaz 21:911-915

112. Schreck G, Surdilovic D, Krüger J (2014) HEPHESTOS: hard material small-batch industrial machining. Robot Scientif. pp 239-244

113. Furtado LFF, Villani E, Trabasso LG, Sutério R (2017) A method to improve the use of 6-dof robots as machine tools. Int J Adv Manuf Technol 92:2487-2502. https://doi.org/10.1007/s00170017-0336-8

114. Matsuoka SI, Shimizu K, Yamazaki N, Oki Y (1999) High-speed end milling of an articulated robot and its characteristics. J Mater
Process Technol 95:83-89. https://doi.org/10.1016/S09240136(99)00315-5

115. Mejri S, Gagnol V, Le TP et al (2016) Dynamic characterization of machining robot and stability analysis. Int J Adv Manuf Technol 82:351-359. https://doi.org/10.1007/s00170-015-7336-3

116. Tratar J, Kopač J (2013) Robot milling of welded structures. J Prod Eng 16:29-32

117. Klimchik A, Bondarenko D, Pashkevich A et al (2012) Compliance error compensation in robotic-based milling. In: Ferrier J-L, Bernard A, Gusikhin O, Madani K (eds) Informatics in control, automation and robotics: 9th international conference. Springer International Publishing, Cham, pp 197-216

118. Klimchik A, Bondarenko D, Pashkevich A, et al (2012) Compensation of tool deflection in robotic-based milling. Icinco 113-122

119. Höfener M, Schüppstuhl T (2014) A method for increasing the accuracy of "on-workpiece" machining with small industrial robots for composite repair. Prod Eng 8:701-709. https://doi.org/10. 1007/s11740-014-0570-y

120. Höfener M, Schüppstuhl T (2014) Small industrial robots for onaircraft repair of composite structures summary/abstract kinematics for on-aircraft machining of composites. In: Conference ISR ROBOTIK. pp 422-427

121. Kothe S, Stürmer SPV, Schmidt HC, et al (2016) Accuracy analysis and error source identification for optimization of robot-based machining systems for aerospace production. SAE Tech Pap 2016-Octob. doi: https://doi.org/10.4271/2016-01-2137

122. Kubela T, Pochyly A, Singule V (2016) Assessment of industrial robots accuracy in relation to accuracy improvement in machining processes. Proc - 2016 IEEE Int power Electron motion control Conf PEMC 2016 720-725. doi: doi:https://doi.org/10.1109/ EPEPEMC.2016.7752083

123. Cordes M, Hintze W (2017) Offline simulation of path deviation due to joint compliance and hysteresis for robot machining. Int $\mathrm{J}$ Adv Manuf Technol 90:1075-1083. https://doi.org/10.1007/ s00170-016-9461-z

124. Tang X, Yan R, Peng F, Liu G, Li H, Wei D, Fan Z (2018) Deformation error prediction and compensation for robot multiaxis milling. In: Chen Z, Mendes A, Yan Y, Chen S (eds) Intelligent robotics and applications. Springer International Publishing, Cham, pp 309-318

125. Slamani M, Gauthier S, Chatelain J-F (2016) Comparison of surface roughness quality obtained by high speed CNC trimming and high speed robotic trimming for CFRP laminate. Robot Comput Integr Manuf 42:63-72. https://doi.org/10.1016/j.rcim.2016.05. 004

126. Slamani M, Chatelain JF (2019) Assessment of the suitability of industrial robots for the machining of carbon-fiber reinforced polymers (CFRPs). J Manuf Process 37:177-195. https://doi.org/ 10.1016/j.jmapro.2018.11.022

127. Barnfather JD, Goodfellow MJ, Abram T (2016) A performance evaluation methodology for robotic machine tools used in large volume manufacturing. Robot Comput Integr Manuf 37:49-56. https://doi.org/10.1016/j.rcim.2015.06.002

128. Barnfather JD, Goodfellow MJ, Abram T (2016) Development and testing of an error compensation algorithm for photogrammetry assisted robotic machining. Measurement 94:561-577. https:// doi.org/10.1016/j.measurement.2016.08.032

129. Lehmann C, Halbauer M, Euhus D, Overbeck D (2012) Milling with industrial robots: strategies to reduce and compensate process force induced accuracy influences. IEEE Int Conf Emerg Technol Fact Autom ETFA doi: https://doi.org/10.1109/ETFA.2012. 6489741

130. Denkena B, Litwinski K, Schönherr M (2013) Innovative drive concept for machining robots. Procedia CIRP 9:67-72. https://doi. org/10.1016/j.procir.2013.06.170 
131. Domrös DF (2014) Towards autonomous robot machining. In: Conference ISR ROBOTIK. pp 448-453

132. Xie Y, Zou W, Yang Y, Lia J (2018) Design of robotic end-effector for milling force control. IOP Conf Ser Mater Sci Eng 423: 012032. https://doi.org/10.1088/1757-899X/423/1/012032

133. Diaz Posada JR, Schneider U, Pidan S, et al (2016) High accurate robotic drilling with external sensor and compliance model-based compensation. Proc - IEEE Int Conf robot autom 3901-3907 . doi: https://doi.org/10.1109/ICRA.2016.7487579

134. Qin C, Tao J, Wang M, Liu C (2016) A novel approach for the acquisition of vibration signals of the end effector in robotic drilling. AUS 2016-2016 IEEE/CSAA Int Conf Aircr Util Syst 522526. doi: https://doi.org/10.1109/AUS.2016.7748106

135. Rosa DGG, Feiteira JFS, Lopes AM, de Abreu PAF (2017) Analysis and implementation of a force control strategy for drilling operations with an industrial robot. J Braz Soc Mech Sci Eng 39:4749-4756. https://doi.org/10.1007/s40430-017-0913-7

136. Brunete A, Gambao E, Koskinen J, Heikkilä T, Kaldestad KB, Tyapin I, Hovland G, Surdilovic D, Hernando M, Bottero A, Anton S (2017) Hard material small-batch industrial machining robot. Robot Comput Integr Manuf 000:1-15. https://doi.org/10. 1016/j.rcim.2017.11.004

137. Leali F, Vergnano A, Pini F, Pellicciari M, Berselli G (2016) A workcell calibration method for enhancing accuracy in robot machining of aerospace parts. Int J Adv Manuf Technol 85:47-55. https://doi.org/10.1007/s00170-014-6025-y

138. Solvang B, Refsahl LK, Sziebig G (2009) STEP-NC based industrial robot CAM system. IFAC Proc 42:245-250. https://doi.org/ 10.3182/20090909-4-JP-2010.00043

139. Lijin F, Li LI, Guoxun W (2017) Integration of cutting robot with CAD/CAM system based on STEP-NC. 868:93-98 . doi: https:// doi.org/10.4028/www.scientific.net/AMM.868.93

140. Rea Minango SN, Ferreira JCE (2017) Combining the STEP-NC standard and forward and inverse kinematics methods for generating manufacturing tool paths for serial and hybrid robots. Int $\mathrm{J}$ Comput Integr Manuf 30:1203-1223. https://doi.org/10.1080/ 0951192X.2017.1305507
141. Zivanovic S, Slavkovic N, Milutinovic D (2018) An approach for applying STEP-NC in robot machining. Robot Comput Integr Manuf 49:361-373. https://doi.org/10.1016/j.rcim.2017.08.009

142. Toquica JS, živanović S, Alvares AJ, Bonnard R (2018) A STEPNC compliant robotic machining platform for advanced manufacturing. Int J Adv Manuf Technol 95:3839-3854. https:// doi.org/10.1007/s00170-017-1466-8

143. Huynh HN, Riviere-Lorphevre E, Verlinden O (2016) Milling simulations with a 3-DOF flexible. Int $\mathrm{J}$ Mech aerospace Ind Mechatron Manuf Eng 10:1543-1552

144. Huynh HN, Kouroussis G, Verlinden O (2018) Modal updating of a 6-axis robot for milling application. In: 25th international congress on sound and vibration. pp 1-8

145. Uhlmann E, Reinkober S, Hollerbach T (2016) Energy efficient usage of industrial robots for machining processes. Procedia CIRP 48:206-211. https://doi.org/10.1016/j.procir. 2016.03.241

146. Denkena B, Brüning J, Windels L, Euhus D, Kirsch S, Overbeck D, Lepper T (2017) Holistic process planning chain for robot machining. Prod Eng 11:715-722. https://doi.org/10.1007/ s11740-017-0771-2

147. Lee R-S, Tsai J-P, Lee J-N, Kao YC, Lin GCI, Lu TF (2000) Collaborative virtual cutting verification and remote robot machining through the Internet. Proc Instn Mech Engre 214:635-644

148. Choi S, Cho CN, Kim H-J (2015) Development of hexapod robot for machining. In: 15th international conference on control, automation and systems. pp 738-740

149. Lei P, Zheng L (2017) An automated in-situ alignment approach for finish machining assembly interfaces of large-scale components. Robot Comput Integr Manuf 46:130-143. https://doi.org/ 10.1016/j.rcim.2017.01.004

Publisher's note Springer Nature remains neutral with regard to jurisdictional claims in published maps and institutional affiliations. 